\title{
Correction to: Music of metagenomics-a review of its applications, analysis pipeline, and associated tools
}

\author{
Bilal Wajid ${ }^{1,2,3,4} \cdot$ Faria Anwar $^{5} \cdot$ Imran Wajid $^{2,6} \cdot$ Haseeb Nisar $^{7,8} \cdot$ Sharoze Meraj $^{2} \cdot$ Ali Zafar $^{2}$. \\ Mustafa Kamal Al-Shawaqfeh ${ }^{9} \cdot$ Ali Riza Ekti $^{10} \cdot$ Asia Khatoon $^{8} \cdot$ Jan S. Suchodolski ${ }^{11}$
}

Published online: 18 November 2021

( The Author(s), under exclusive licence to Springer-Verlag GmbH Germany, part of Springer Nature 20212021

\section{Correction to: Functional \& Integrative Genomics (2021) https://doi.org/10.1007/s10142-021-00810-y}

The co-author Imran Wajid would like to update his second affiliation address to "School of Social Sciences, Istanbul Commerce University, Istanbul, Turkey".

The original article has been corrected.

Publisher's note Springer Nature remains neutral with regard to jurisdictional claims in published maps and institutional affiliations.

The original article can be found online at https://doi.org/10.1007/ s10142-021-00810-y.

Bilal Wajid
bilalwajidabbas@hotmail.com
Department of Electrical Engineering, University
of Engineering and Technology, Lahore, Pakistan

2 Muhammad Ibn Musa Al-Khwarizmi Research and Development Division, Sabz-Qalam, Lahore, Pakistan

3 Department of Computer Science, University of Management \& Technology (UMT), Lahore, Pakistan

4 Department of Electrical Engineering, Istanbul Commerce University, Istanbul, Turkey

5 Mayo Hospital, Out-Patient DepartmentLahore, Pakistan

6 School of Social Sciences, Istanbul Commerce University, Istanbul, Turkey
7 Office of Research Innovation and Commercialization, UMT, Lahore, Pakistan

8 School of Biochemistry and Biotechnology, University of the Punjab, Lahore, Pakistan

9 Department of Electrical Engineering, German Jordanian University, Amman, Jordan

10 Department and Electrical and Electronics Engineering, Balikesir University, Balikesir, Turkey

11 College of Veterinary Medicine and Biomedical Sciences, Texas A \& M University, College Station, TX, USA 